\section{Statin Therapy Decreases Myocardial Function as Evaluated Via Strain Imaging}

\author{
Jack Rubinstein, MD; Feras Aloka, MD; George S. Abela, MD, MSc
}

Cardiology Division, Department of Medicine (Rubinstein, Abela), Michigan State University, East Lansing, Michigan; Internal Medicine Division, Department of Cardiology (Aloka), Michigan State University, East Lansing, Michigan
Address for correspondence: Jack Rubinstein, MD Cardiology Division A205 Clinical Center Michigan State University East Lansing, MI 48824 jackrubinstein@yahoo.com

Objectives: The purpose of this study was to evaluate the effects of statin therapy on myocardial function as measured with echocardiography with tissue Doppler imaging (TDI) and strain imaging (SI) independent of its lipid-lowering effect.

Background: Statin use is known to improve outcomes in the primary and secondary prevention of ischemic heart disease, but their use is also associated with myopathy, muscle weakness and in rare cases, rhabdomyolysis. We sought to evaluate whether TDI and SI is able to identify changes in myocardial function associated with statin use.

Methods: Myocardial function was evaluated in 28 patients via echocardiography with TDI and SI. We identified 12 patients ( 5 females) without overt cardiovascular disease (including hypertension, smoking, and diabetes) that were on statin therapy and compared their echocardiographic findings with 16 ( 12 females) age, sex, and cholesterol-profile-matched controls. Tissue Doppler imaging parameters of diastolic $\left(E^{\prime} / A^{\prime}\right.$ and $\left.E / E^{\prime}\right)$ and systolic ( $\mathrm{S}^{\prime}$ ) function were measured. Regional systolic function was obtained by SI in 4-chamber, 2-chamber, long axis, and average global views.

Results: There was no significant difference in myocardial function as measured by Doppler and minor differences as measured via TDI among the 2 groups. There was significantly better function noted with $\mathrm{SI}$ in the control group vs the statin group in the 4 -chamber $(-19.05 \% \pm 2.45 \%$ vs $-16.47 \% \pm 2.37 \%$ $\mathrm{P}=0.009)$, 2-chamber $(-20.30 \% \pm 2.66 \%$ vs $-17.45 \% \pm 4.29 \% \mathrm{P}=0.03)$, long axis $(-17.63 \% \pm 3.79 \%$ vs $-13.83 \% \pm 3.74 \% \mathrm{P}=0.01)$, and average global $(-19.0 \% \pm 2.07 \%$ vs $-15.91 \% \pm 2.81 \% \mathrm{P}=0.004)$ views. Conclusion: Statin therapy is associated with decreased myocardial function as evaluated with SI.

\section{Introduction}

Several studies have demonstrated that 3-hydroxy-3methylglutaryl coenzyme A reductase inhibitors (statins) significantly improve cardiovascular outcomes in ischemic heart disease. ${ }^{1-5}$ Furthermore, statin use has also been shown to improve outcomes in other diseases. ${ }^{6,7}$ But the cholesterol lowering effect of statins alone does not seem to fully account for the varied clinical benefits that patients derive from their use. Studies that have focused on the pleiotropic effects of statins ${ }^{8,9}$ have yet to fully elucidate the mechanism by which these added positive effects occur.

In contrast, there are also studies evaluating the association between the use of statin medications and muscle weakness, ${ }^{10,11}$ myalgia, ${ }^{12,13}$ and rhabdomyolisis. ${ }^{14-16}$ Similarly, there are several mechanisms by which statin medications may have adverse effects on muscles, ${ }^{17}$ but again, no clear mechanism has been established.

We sought to evaluate these seemingly contradictory findings with a case-control study of myocardial function with advanced echocardiographic imaging. Advanced echocardiographic imaging with tissue Doppler (TDI) and speckle tracking technology have gained popularity in the clinical and research realms as highly efficient methods to quantify myocardial function ${ }^{18-20}$ and have been used with both human and animal models of hypercholesterolemia to evaluate for minor changes in both systolic and diastolic function..$^{21,22}$ Speckle tracking technology uses similar technology to further quantify systolic function in very small areas of the myocardium reflecting left ventricle (LV) tissue deformation or strain..$^{23}$ Recently, TDI and speckle tracking derived strain imaging (SI) imaging have been used to evaluate the improved left ventricular response in humans and animals on statin therapy that has correlated with decreasing serum cholesterol values. ${ }^{24-27}$

\section{Methods}

\section{Clinical Study Group}

The study protocol was approved by the institutional review board of Michigan State University. We studied 12 otherwise healthy subjects who had received a full physical exam, diagnosis of hypercholesterolemia treated only with statin therapy for at least 6 months for primary prevention of coronary artery disease (CAD), and a fasting lipid profile within 3 months of the echocardiographic study. These cases were compared with 16 age, sex, systolic and diastolic blood pressure, high-density lipoprotein cholesterol (HDL-C), low-density lipoprotein cholesterol (LDL-C), and total cholesterol-matched controls who had never been treated with statin therapy. 
Inclusion criteria were: normal blood pressure, as well as a normal physical exam, negative family history for early $\mathrm{CAD}$, and nonsmokers. They were excluded if they had any left ventricular conduction abnormalities, a history of prior coronary intervention, an ejection fraction of less than 50\%, or clinically significant valvular disease.

All patients had a negative history of $\mathrm{CAD}$ as assessed clinically (asymptomatic with rest and exercise) or via stress test (normal stress test with either nuclear or echocardiographic imaging) prior to the echocardiographic study.

\section{Echocardiographic Protocol}

All subjects underwent a standard echocardiographic examination with a $5 \mathrm{MHz}$ probe (Vivid 7/Vingmed General Electric, Milwaukee, WI) with 2D, M-mode, and color Doppler; furthermore all had live acquisition of TDI obtained from an apical 4-chamber view and images for SI analysis from a 2-chamber, 4-chamber, and long axis view from the apical window.

Doppler imaging of the mitral valve was obtained from the apical 4-chamber view. From the mitral inflow velocity image, the following measurements were obtained: peak $\mathrm{E}$ and peak $\mathrm{A}$ waves, E/A ratio, E-wave acceleration, and deceleration times.

TDI imaging was performed from an apical 4-chamber view with very low gain and a $5 \mathrm{~mm}$ tissue sampling volume at the mitral annulus from both septal and lateral walls. ${ }^{28}$ From the acquired images, the following diastolic function parameters were measured: $\mathrm{E}^{\prime}, \mathrm{A}^{\prime}, \mathrm{E}^{\prime} / \mathrm{A}^{\prime}$, and $\mathrm{E} / \mathrm{E}^{\prime}$ ratio wave ratio; the systolic parameter measured was $\mathrm{S}^{\prime}$ (Figure 1). 29-31

For strain analysis, the apical 2-chamber, 4-chamber, and long axis images were obtained at more than 36 frames per second and were subsequently processed and analyzed as per the manufacturer instructions on a GE Echopac7 workstation (General Electric, Milwaukee, WI). The values obtained from processing were local SI in the 17 segment bull's-eye image, regional SI from the separate windows (apical long axis, 4-chamber, and 2-chamber views), and the aggregate summed strain score (Figure 2).

All images were acquired by a single technician and were processed by a single physician, both of whom were blinded as to the other's results. The subsequent images and values were confirmed by a separate and blinded physician.

\section{Statistical Analysis}

Matching analysis was performed with a student $t$ test for differences based on age, sex, systolic and diastolic blood pressure, HDL-C, LDL-C, and total cholesterol with statistical significance between the groups of $P<0.05$. Furthermore, comparisons were also analyzed with a student $t$ test and a value of $P<0.05$ was deemed to be statistically significant.

\section{Results}

The baseline demographic values of the subjects are presented in Table 1 . There were no differences noted in LV thickness between the 2 groups in either the septal (1.01 \pm 0.11 vs $1.11 \pm 0.26, \mathrm{P}=0.15)$ or posterior wall $(0.99 \pm 0.14$ vs $1.07 \pm 0.17, \mathrm{P}=0.13$ ), and only 1 patient (in the statin group) met echocardiographic criteria for left ventricular hypertrophy.

There was statistically significant worsening of diastolic function parameters in the statin group as measured via TDI in the lateral wall but not the septum (Table 2).

There were no significant differences in diastolic function noted between the 2 groups as measured by Doppler imaging; including $\mathrm{E}$ wave ( 0.76 vs $0.74, \mathrm{P}=0.36)$, E-wave deceleration time (262.88 vs $263.83, \mathrm{P}=0.48)$, and $\mathrm{E} / \mathrm{A}$ ratio (1.33 vs $1.12, \mathrm{P}=0.06)$.

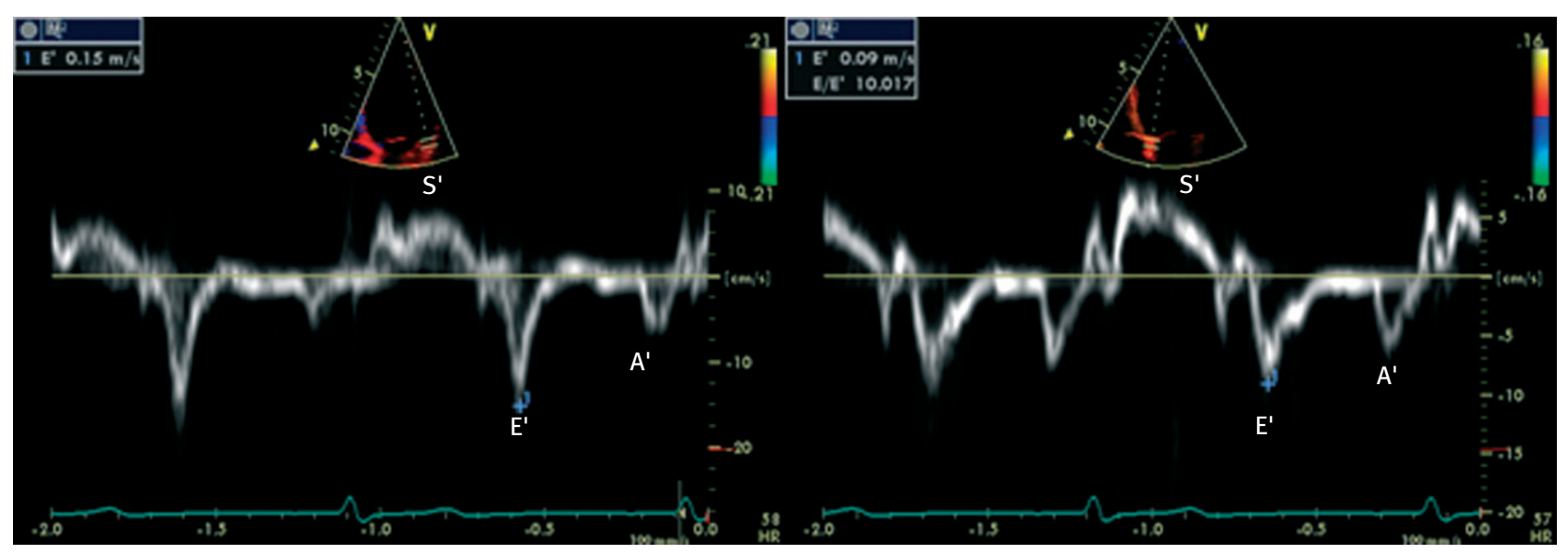

Figure 1. Tissue Doppler images showing $\mathrm{E}^{\prime}$ and $\mathrm{A}^{\prime}$ as markers of diastolic function and $\mathrm{S}^{\prime}$ as a marker of systolic function in both septal (right) and lateral (left) walls. 


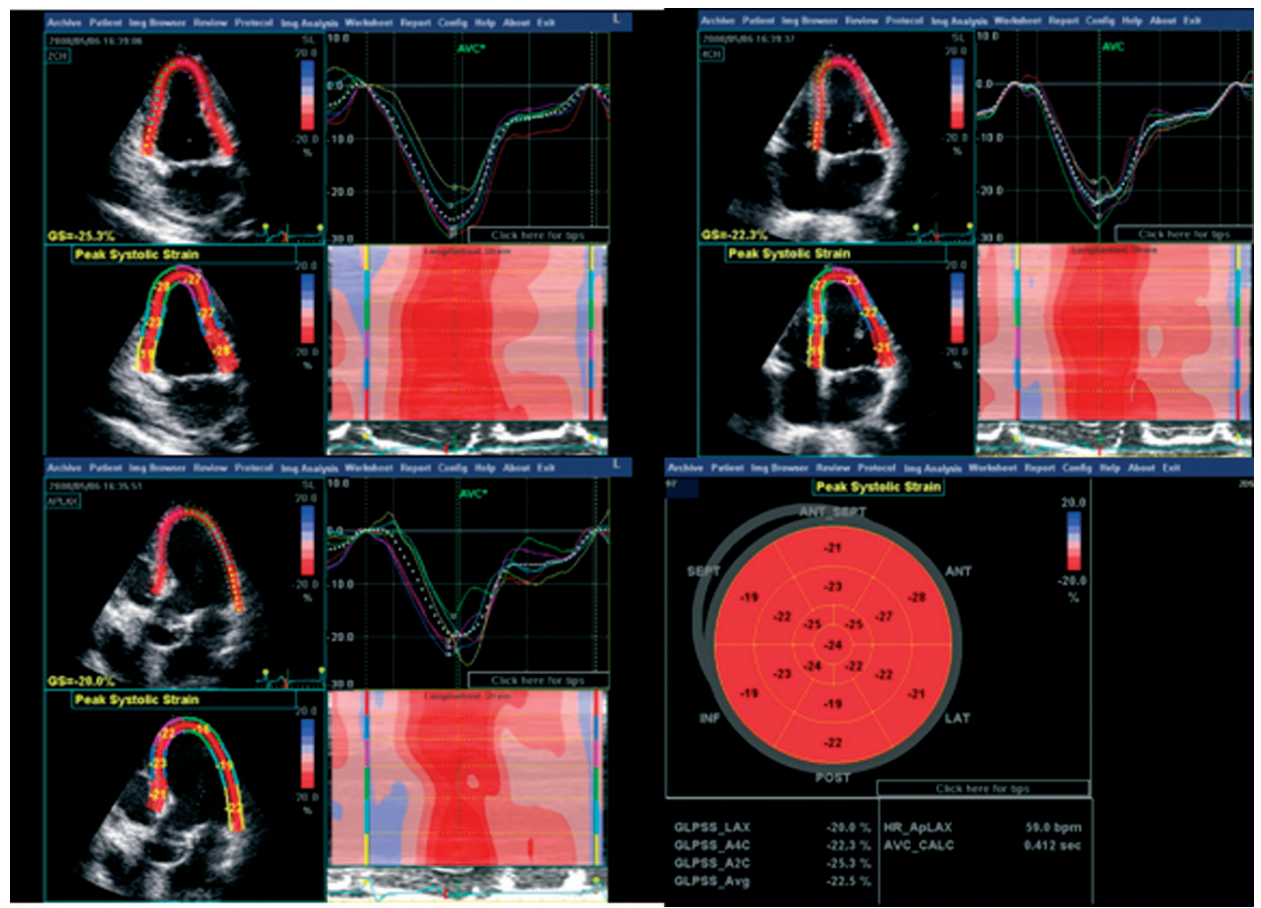

Figure 2. Strain imaging with normal contraction in control subject. Upper left, 2-chamber view; upper right, 4-chamber view; lower left, apical long axis view; and lower right, the computer-generated bull's eye image.

Table 1. Demographic values of study population

\begin{tabular}{|lrr|}
\hline Variable & \multicolumn{1}{c}{$\begin{array}{c}\text { Average in } \\
\text { Subjects Not } \\
\text { on Statin }\end{array}$} & \multicolumn{1}{c|}{$\begin{array}{c}\text { Average in } \\
\text { Subjects on } \\
\text { Statin }\end{array}$} \\
\hline Age & $55.44 \pm 11.40$ & $60.75 \pm 13.81$ \\
\hline BMI & $27.11 \pm 5.30$ & $30.47 \pm 6.37$ \\
\hline SBP & $115 \pm 14.91$ & $123 \pm 15.78$ \\
\hline DBP & $70.56 \pm 13.61$ & $77 \pm 13.33$ \\
\hline HDL-C & $55.25 \pm 11.80$ & $50.67 \pm 11.73$ \\
\hline LDL-C & $120.69 \pm 24.21$ & $119 \pm 37.80$ \\
\hline Non-HDL & $142 \pm 27.21$ & $151.17 \pm 44.59$ \\
\hline Triglycerides & $a$
\end{tabular}

There was a significant decrease in S-R measured function in the statin group (Figure 3) compared to the nonstatin group. These differences were noted in all 3 views; apical long axis $(-17.63 \% \pm 3.79 \%$ vs $-13.83 \% \pm 3.74 \% \mathrm{P}=0.01)$, 2 -chamber $(-20.30 \% \pm 2.66 \%$ vs $-17.45 \% \pm 4.29 \% \mathrm{P}=0.03)$, and 4 -chamber $(-19.05 \% \pm 2.45 \%$ vs $-16.47 \% \pm 2.37 \% \mathrm{P}=$ $0.009)$, as well as in the sum SI score $(-19.0 \% \pm 2.07 \%$ vs $-15.91 \% \pm 2.81 \% \mathrm{P}=0.004$; Figure 4$)$.

\section{Discussion}

Our study finds that statin therapy is associated with a small but statistically significant decrease in myocardial function as measured by TDI in the lateral wall and a larger and more significant decrease when evaluated with SI. This is consistent with several other studies that have shown that statin therapy causes myopathy in noncardiac muscle. ${ }^{10-17}$ In contrast, our study is in direct contradiction to previously published data that imply that statin therapy improves myocardial function in nonheart failure patients. ${ }^{24-26}$ These studies have used similar echocardiographic techniques as the techniques used in this trial and one study used SI, though without 3D reconstruction with bull's-eye images. ${ }^{24}$

The fact that peripheral muscles are damaged-sometimes severely - by the same medications that improve cardiac muscle function seems contradictory. The studies that have shown increased incidence of myopathy and decreased muscle strength with statin medications are consistent: ${ }^{11-17}$ as are the studies that have shown improved

686 Clin. Cardiol. 32, 12, 684-689 (2009)

J. Rubinstein et al: Statin therapy decreases myocardial function as evaluated via strain imaging Published online in Wiley InterScience. (www.interscience.wiley.com)

DOI:10.1002/clc.20644 @ 2009 Wiley Periodicals, Inc. 
Table 2. Tissue Doppler parameters of systolic and diastolic function with and without statin therapy

\begin{tabular}{|c|c|c|c|c|c|c|}
\hline Variable & $\begin{array}{c}\text { Septal Wall } \\
\text { Without Statin }\end{array}$ & $\begin{array}{l}\text { Septal Wall } \\
\text { With Statin }\end{array}$ & $P$ Value & $\begin{array}{l}\text { Lateral Wall } \\
\text { Without Statin }\end{array}$ & $\begin{array}{l}\text { Lateral Wall } \\
\text { With Statin }\end{array}$ & $P$ Value \\
\hline$S^{\prime}$ & $0.07 \pm 0.01$ & $0.07 \pm 0.01$ & .42 & $0.09 \pm 0.02$ & $0.09 \pm 0.02$ & .16 \\
\hline$E^{\prime}$ & $0.09 \pm 0.03$ & $0.08 \pm 0.03$ & .21 & $0.12 \pm 0.03$ & $0.10 \pm 0.03$ & .04 \\
\hline$E^{\prime} / A^{\prime}$ & $0.96 \pm 0.33$ & $0.87 \pm 0.41$ & .28 & $1.30 \pm 0.55$ & $1.04 \pm 0.50$ & .1 \\
\hline$E / E^{\prime}$ & $9.38 \pm 2.63$ & $10.08 \pm 2.42$ & .23 & $6.48 \pm 1.83$ & $8.14 \pm 2.80$ & .05 \\
\hline
\end{tabular}

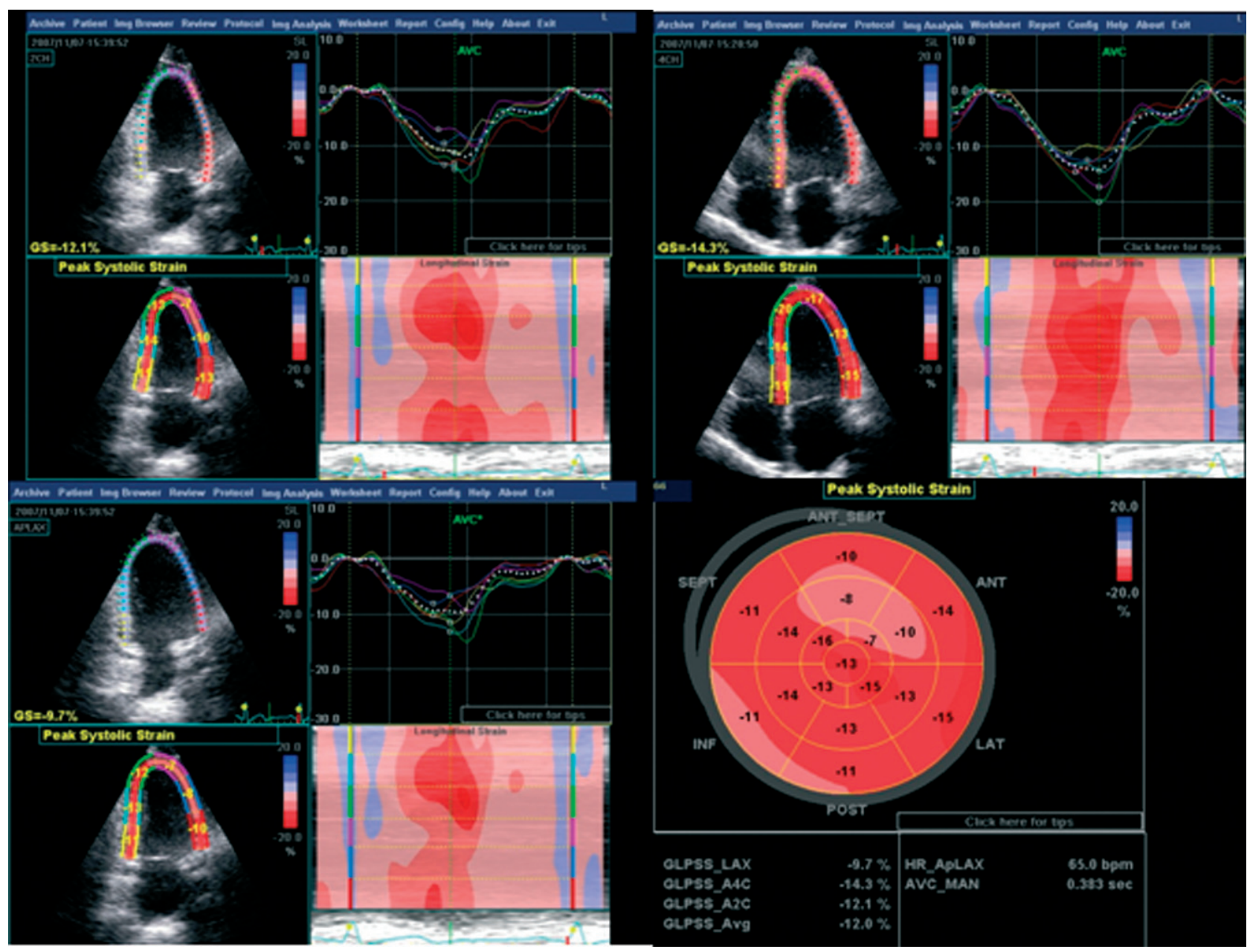

Figure 3. Strain imaging with abnormal contraction in statin subject. Upper left, 2-chamber view; upper right, 4-chamber view; lower left, apical long axis view; and lower right, the computer generated bull's eye image.

myocardial function and outcomes in patients taking statins for a variety of indications. ${ }^{24-26}$

This study though, separates the cholesterol-lowering effect of statins by using comprehensively matched cases (that had been on statin therapy for at least 6 mos) and controls. This is a critical difference, as it has been shown that hypercholesterolemia in and of itself is capable of causing myocardial dysfunction, ${ }^{24-26}$ and hence any medication that decreases serum cholesterol levels is likely to show improved myocardial function. This study suggests 


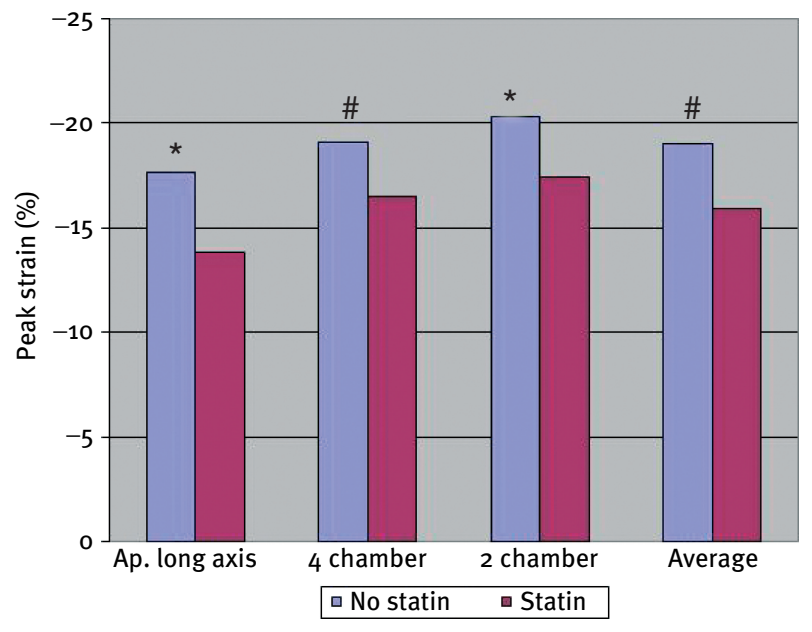

Figure 4. The effect of statin use on SI in apical long axis, 2-chamber, 4-chamber, and average views.

$* \mathrm{P}<0.05$

$\# P<0.001$.

that one of the pleiotropic effects of statins is decreased systolic function as measured by SI.

This study is limited by a relatively small sample size, but the seemingly negative inotropic effect observed is consistent with decreased myocardial workload not unlike those seen with $\beta$-blockers and afterload reducing medications. ${ }^{32,33}$ The observed decrease in the intensity of the myocardial function can potentially account for the myocardial protection that has been proven with statin therapy and acute ischemic events and coronary interventions. ${ }^{34,35}$

Lastly, the changes that were noted with TDI were borderline significant and not nearly as sensitive as those seen with SI. Hence, SI may be used in the evaluation of other medications that seek to evaluate for cardio-protective effects.

\section{Conclusion}

Statins cause decrease in myocardial function, not unlike that seen in peripheral muscle, as measured primarily by SI. This may partially explain the positive pleiotropic cardiovascular effects of statins beyond cholesterol lowering.

\section{Acknowledgments}

The authors would like to thank all the patients who participated in this study and a special thanks to Linda St. John for her tireless efforts in obtaining pristine echocardiographic images.

\section{References}

1. Jukema JW, Bruschke AVG, van Boven AJ, et al. Effects of lipid lowering by pravastatin on progression and regression of coronary artery disease in symptomatic men with normal to moderately elevated serum cholesterol levels: The Regression Growth Evaluation Statin Study (REGRESS). Circulation. 1995;91: 2528-2540.

2. Schartl M, Bocksch W, Koschyk DH, et al. Use of intravascular ultrasound to compare effects of different strategies of lipidlowering therapy on plaque volume and composition in patients with coronary artery disease. Circulation. 2001;104:387-392.

3. Vaughan CJ, Murphy MB, Buckley BM. Statins do more than just lower cholesterol. Lancet. 1996;348(9034):1079-1082.

4. Maycock CAA, Muhlestein JB, Horne BD, et al. Statin therapy is associated with reduced mortality across all age groups of individuals with significant coronary disease, including very elderly patients. J Am Coll Cardiol. 2002;40:1777-1785.

5. The Long-Term Intervention with Pravastatin in Ischaemic Disease (LIPID) Study Group. Prevention of cardiovascular events and death with pravastatin in patients with coronary heart disease and a broad range of initial cholesterol levels. N Engl J Med. 1998;339(19):1349-1357.

6. Rosenhek R, Rader F, Loho N, et al. Statins but not angiotensinconverting enzyme inhibitors delay progression of aortic stenosis. Circulation. 2004;110:1291-1295.

7. Young-Xu Y, Jabbour S, Goldberg R, et al. Usefulness of statin drugs in protecting against atrial fibrillation in patients with coronary artery disease. Am J Cardiol. 2003;92(12):1379-1383.

8. Reilly SD, Litovsky SH, Steinkampf MP, et al. Statins improve human coronary atherosclerotic plaque morphology. Tex Heart Inst J. 2008;35(2):99-103.

9. Chia S, Raffel OC, Takano M, et al. Association of statin therapy with reduced coronary plaque rupture: an optical coherence tomography study. Coron Artery Dis. 2008;19(4):237-242.

10. Asbach P, Paetsch I, Stawowy P, et al. Statin-associated focal myositis. Int J Cardiol. 2007;133(1):e33-e34.

11. Needham M, Fabian V, Knezevic W, et al. Progressive myopathy with up-regulation of MHC-I associated with statin therapy. Neuromuscul Disord. 2007;17(2):194-200.

12. Pasternak RC, Smith SC, Bairey-Merz CN, et al. ACC/AHA/ NHLBI clinical advisory on the use and safety of statins. $J$ Am Coll Cardiol. 2002;40(3):567-572.

13. Ballantyne CM, Corsini A, Davidson MH, et al. Risk for myopathy with statin therapy in high-risk patients. Arch Intern Med. 2003;163:553-564

14. Antons KA, Williams CD, Baker SK, et al. Clinical perspectives of statin-induced rhabdomyolysis. Am J Med. 2006;119:400-409.

15. Graham DJ, Staffa JA, Shatin D, et al. Incidence of hospitalized rhabdomyolysis in patients treated with lipid-lowering drugs. JAMA. 2004;292:2585-2590.

16. Staffa, JA, Chang, J, Green, L. Cerivastatin and reports of fatal rhabdomyolysis. N Engl J Med. 2002;346:539-540.

17. Baker SK, Tarnopolsky MA. Statin myopathies: pathophysiologic and clinical perspectives. Clin Invest Med. 2001;24(5):258-272.

18. Streb W, Duszańska A, Stabry la-Deska J, et al. The comparison of contrast echocardiography and tissue Doppler imaging for evaluation of reperfused myocardium in patients with acute anterior myocardial infarction. Cardiol J. 2008;15(6):548-554.

19. Marcucci C, Lauer R, Mahajan A. New echocardiographic techniques for evaluating left ventricular myocardial function. Semin Cardiothorac Vasc Anesth. 2008;12(4):228-247.

20. Marsan NA, Westenberg JJ, Tops LF, et al. Comparison between tissue Doppler imaging and velocity-encoded magnetic resonance imaging for measurement of myocardial velocities, assessment of left ventricular dyssynchrony, and estimation of left ventricular filling pressures in patients with ischemic cardiomyopathy. Am J Cardiol. 2008;102(10):1366-1372.

21. St. Vrain J, Bilhorn K, Kurup S, et al. Strain imaging using speckle tracking in the cardiometabolic syndrome: method and utility. J CardioMetabolic Syn. 2008;3(4):258-261.

688 Clin. Cardiol. 32, 12, 684-689 (2009)

J. Rubinstein et al: Statin therapy decreases myocardial function as evaluated via strain imaging

Published online in Wiley InterScience. (www.interscience.wiley.com)

DOI:10.1002/clc.20644 @ 2009 Wiley Periodicals, Inc. 
22. Lin LC, Wu CC, Yeh HI, et al. Downregulated myocardial connexin 43 and suppressed contractility in rabbits subjected to a cholesterol-enriched diet. Laboratory Investigation. 2005;85: 1224-1237.

23. Abraham TP, Nishimura RA. Myocardial strain: can we finally measure contractility? J Am Coll Cardiol. 2001;37:731.

24. Mizuguchi Y, Oishi Y, Miyoshi H, et al. Impact of statin therapy on left ventricular function and carotid arterial stiffness in patients with hypercholesterolemia. Circ J. 2008;72(4):538-544.

25. Talini E, Di Bello V, Bianchi C, et al. Early impairment of left ventricular function in hypercholesterolemia and its reversibility after short term treatment with rosuvastatin: a preliminary echocardiographic study. Atherosclerosis. 2008;197(1): 346-354.

26. Bountioukos M, Rizzello V, Krenning BJ, et al. Effect of atorvastatin on myocardial contractile reserve assessed by tissue Doppler imaging in moderately hypercholesterolemic patients without heart disease. Am J Cardiol. 2003;92(5):613-616.

27. Patel R, Nagueh SF, Tsybouleva N, et al. Simvastatin induces regression of cardiac hypertrophy and fibrosis and improves cardiac function in a transgenic rabbit model of human hypertrophic cardiomyopathy. Circulation. 2001;104(3):317-324.

28. Sohn DW, Chai IH, Lee DJ, et al. Assessment of mitral annulus velocity by Doppler tissue imaging in the evaluation of left ventricular diastolic function. J Am Coll Cardiol. 1997;30(2): $474-480$.
29. Nagueh SF, Middleton KJ, Kopelen HA, et al. Doppler tissue imaging: a noninvasive technique for evaluation of left ventricular relaxation and estimation of filling pressures. J Am Coll Cardiol. 1997;30(6):1527-1533

30. Ommen SR, Nishimura RA, Appleton CP, et al. Clinical utility of doppler echocardiography and tissue doppler imaging in the estimation of left ventricular filling pressures: a comparative simultaneous doppler-catheterization study. Circulation. 2000;102:1788.

31. Draeger A, Monastyrskaya K, Mohaupt M, et al. Statin therapy induces ultrastructural damage in skeletal muscle in patients without myalgia. J Pathol. 2006;210(1):94-102.

32. Shan K, Bick RJ, Poindexter BJ, et al. Relation of tissue Doppler derived myocardial velocities to myocardial structure and betaadrenergic receptor density in humans. J Am Coll Cardiol. 2000; 36(3):891-896.

33. Wang M, Yip GWK, Wang A, et al. Tissue Doppler imaging provides incremental prognostic value in patients with systemic hypertension and left ventricular hypertrophy. J Hyperten. 2005;23(1): 183-191.

34. Mulukutla S, Marroquin O, Smith C, et al. Effect of statin therapy prior to elective percutaneous coronary intervention on frequency of periprocedural myocardial injury. Am J Cardiol. 2004;94(11): 1363-1366.

35. Okazaki S, Yokoyama T, Miyauchi K, et al. Early statin treatment in patients with acute coronary syndrome. Circulation. 2004;110: 1061-1068. 